\title{
The effects of types of degradable polymers on porcine chondrocyte adhesion, proliferation and gene expression
}

\author{
Wei-Bor Tsai · Chun-Hong Chen · Jing-Fu Chen · \\ Ken-Yuan Chang
}

Received: 3 September 2004 / Accepted: 7 July 2005

(C) Springer Science + Business Media, LLC 2006

\begin{abstract}
Understanding how a specific biomaterial may influence chondrocyte adhesion, proliferation and gene expression is important in cartilage tissue engineering. In this study several biodegradable polymers that are commonly used in tissue engineering were evaluated with respect to their influence on chondrocyte attachment, proliferation and gene expression. Primary cultures of porcine chondrocytes were performed in films made of poly-L-lactic acid (PLLA), poly-D,L-lactic acid (PDLLA), poly-(lactideco-glycolide) (PLGA), or polycaprolactone (PCL). Chondrocytes adhered to PDLLA or PLGA after 1-day incubation better than to PLLA or PCL. After 7 or 14 day culture, the cell numbers on PDLLA or PLGA was still higher than PLLA or PCL. The results suggested that cell attachment and growth might depend on degradation rate of biodegradable polymers. Along with the fact that PDLLA or PLGA supported expression of chondrocyte specific genes more than PLLA or PCL, the former two materials seemed to be more suitable for cartilage tissue engineering than the latter ones. Besides, we found that chondrocyte phenotype prior to seeding was important in the expression of ECM proteins.
\end{abstract}

W.-B. Tsai $(\bowtie) \cdot$ C.-H. Chen

Department of Chemical Engineering, National Taiwan

University, No. 1, Roosevelt Rd., Sec. 4, Taipei, 106, Taiwan

Tel.: 886-2-3366-3996

Fax: 886-2-2362-3040

e-mail:weibortsai@ccms.ntu.edu.tw

J.-F. Chen · K.-Y. Chang

ITRI, Biomedical Engineering Center, Hsinchu 300, Taiwan

\section{Introduction}

Articular cartilage, a unique tissue lacking nerves, blood vessels and lymphatic system, covers articulating ends of joints and resists weight loading. As cartilage's large ratio of matrix to cells, chondrocytes are scattered in cartilage extracellular matrix (ECM), a highly organized macromolecular framework [1]. Chondrocytes regulate production, organization and degradation of ECM that is responsible for cartilage's mechanical functions. It is generally agreed that adult articular cartilage with relatively low or no turnover is not capable of repairing itself [2], although complete recovery of small full thickness lesions was found in young animals [3]. As a result, injured articular cartilage would further degenerate and eventually turn into osteoarthritis. Finally, the damaged knee needs to be replaced by a metal prosthesis. Therefore, articular cartilage repair has been one of primary targets for a newly-emerging biomedical field - tissue engineering.

Three important elements in tissue engineering include cells, scaffolds, and biological signals [4]. Scaffolds play a role like ECM in natural tissues, which support cell attachment, proliferation, and differentiation. The architectural design of scaffolds, mimicking ECM, is usually a highly porous and three-dimensional structure which allows enough cells to accommodate and grow inside, and organizes cells into a three-dimensional tissue [5]. One of the major challenges in tissue engineering is to find a suitable material and fabricate into scaffolds of defined architecture to guide cell growth and development.

A suitable biodegradable material for fabricating tissue engineering scaffolds must support cell adhesion, growth, and differentiated phenotype. Among the materials used for scaffold fabrication, the most favourable materials 
have been synthetic degradable polymers. Their advantages include controllable degradation rate, high reproducibility, and easy fabrication into specific shapes [6]. A variety of synthetic biodegradable materials have been explored in scaffolding for cartilage tissue engineering, including polyesters like poly-L-lactic acid (PLLA), poly-glycolic acid (PGA), their copolymer (PLGA), and polycaprolactone (PCL). It is generally thought that choices in scaffold materials potentially decide outcome of cartilage tissue engineering [5, 711]. For example, Freed et al. [8] showed that chondrocytes grew in vitro in three-dimensional PGA scaffolds approximately twice as fast as in PLLA scaffolds. Furthermore, chondrocytes grown in PGA scaffolds produced a cartilage ECM component, sulfated glycosaminoglycan (S-GAG), at a high steady rate, while those grown in PLLA scaffolds only produced minimal amounts of S-GAG. However, the conclusion seems unequivocal. In another study, nonwoven PLA scaffolds were found more biocompatible with chondrocytes than nonwoven PGA ones [12].

The effect of scaffolds on chondrocyte performance may depend on not only materials types and sources but also in scaffold formats and structures. In Freed et al.'s study [8], PGA scaffolds were made of PGA fiber (14 $\mu$ m diameter) as a non-woven mesh, while PLLA scaffolds were prepared using a solvent-casting particulate-leaching method. Moreover, porosity of the PGA scaffolds was $97 \%$, while that of the PLLA ones was $91 \%$. Therefore, it is difficult to decipher the effect of material types on chondrocyte growth and ECM production from the results.

Several studies have been focused on evaluating seeding efficiency and growth rates of chondrocytes on several biodegradable polymers [13, 14]. However, success to a functional cartilage tissue engineering product also depends on chondrocyte phenotype. It is well known that when autologous chondrocytes are propagated in vitro, especially in monolayer systems such as dishes and flasks, chondrocytes tend to be de-differentiated. During monolayer expansion, chondrocyte's shape is first changed from characteristically round shape to a spindle fibroblast-like morphology [15]. Next, chondrocytes lose their ability in secreting the cartilage-specific ECM macromolecules, such as type II collagen and aggrecan, and in stead secret type I collagen [16-20]. De-differentiated chondrocytes would lead to formation of mechanically inferior fibrocartilage.

The purpose of this study was to evaluate the effect of biodegradable polymer types on chondrocyte adhesion, proliferation and gene expression. Several commonly used biodegradable polymers were solvent-cast to glass dishes. Chondrocytes were then seeded and cultured for up to 2 weeks. Cell adhesion and proliferation were determined as well as the expression of type I collagen, type II collagen and aggrecan genes.

\section{Materials and methods}

Biodegradable polymers

Poly(lactide-co-glycolide) 85:15 w/w (PLGA) and poly(D, L-lactide) (PDLLA) were synthesized via ring-opening polymerization in bulk. $0.01 \%$ Lauryl alcohol and $0.03 \%$ stannous octoate were applied as a chain control agent and catalyst, respectively. Polymerization was carried out for $6 \mathrm{hrs}$ at $180^{\circ} \mathrm{C}$. The molecular weights of the polymers were measured by Thermo Separation Product GPC system with tetrahydrofuran as solvent and polystyrene as calibration standards. For PLGA, the determined molecular weights were $M_{n} 10,723$ and $M_{w} 30,986$; For PDLLA, they were $M_{n} 88,341$ and $M_{w} 131,140$.

Poly-L-lactic acid (PLLA, I.V. $8.41 \mathrm{dl} / \mathrm{g}$ ) were purchased from PURAC Inc. Polycaprolactone (PCL) was obtained from Aldrich (cat No. 44074-4, $M_{n}=80,000$ ).

\section{Polymer coating}

Glass dishes (I.D. $6 \mathrm{~cm}$ ) were cleaned with detergent and then rinsed with $0.1 \mathrm{~N} \mathrm{HCl}$ followed by rinse with water thrice. After air-dried, glass dishes were treated with $1 \mathrm{ml}$ Plus One ${ }^{\mathrm{TM}}$ Repel-silane ES (Amersham Biosciences, cat. no. 17-1332-01) for $10 \mathrm{~min}$ at room temperature. The treated glass dishes were then rinsed with methanol once and water twice, and finally air-dried in a hood.

Each polymer was dissolved in dichloromethane to a $15 \mathrm{mg} / \mathrm{ml}$ solution and $1.2 \mathrm{ml}$ of polymer solution was added to each glass dish. A polymer film was formed after dichloromethane was evaporated in a hood, and the residual solvent was further removed in a vacuum oven. Polymer coating was verified by changes in static water contact angle measurement. Static contact angles of water on samples were evaluated at $24^{\circ} \mathrm{C}$ using a contact angle meter with a goniometer. The polymer-coated dishes were ready for cell culture after sterilized with $70 \%$ ethanol and exposed to UV for overnight.

\section{Chondrocyte isolation and culture}

Articular cartilage samples were dissected aseptically from pig (9-10 month old) knee joints which were obtained from a local abattoir. The articular cartilage samples were diced into approximate $1 \mathrm{~mm}^{3}$ pieces in autoclaved phosphate buffered saline (PBS, $137 \mathrm{mM} \mathrm{NaCl}, 2.7 \mathrm{mM} \mathrm{KCl}, 10 \mathrm{mM} \mathrm{Na}_{2} \mathrm{HPO}_{4}$, and $1.8 \mathrm{mM} \mathrm{KK_{2 }} \mathrm{PO}_{4}$, pH 7.4) containing $200 \mu \mathrm{g} / \mathrm{ml}$ gentamicin (Gibco, Cat. no. 1570064) and $25 \mu \mathrm{g} / \mathrm{ml}$ fungizone (Gibco, Cat. no. 1520018). After rinsed with PBS three times, $1 \sim 2$ grams of the cartilage slivers were digested in $10 \mathrm{ml}$ of DMEM/F12 (Gibco, Cat. no. 12400-024) containing $1 \mathrm{mg} / \mathrm{ml}$ hyaluronidase (Sigma, Cat. no. H-3506) and $1 \mathrm{mg} / \mathrm{ml}$ type I 
collagenase (Sigma, Cat. no. C0130) in a $37^{\circ} \mathrm{C}, 5 \% \mathrm{CO}_{2}$ incubator for $18 \mathrm{hrs}$. The digestate was filtered through a $70-\mu \mathrm{m}$ filter cell strainer (Falcon, Cat. No. 352350) to remove undigested cartilage lumps. The filtrate was then centrifuged at $200 \times \mathrm{g}$ for $10 \mathrm{~min}$, and the cell pellet was resuspended in chondrocyte medium (DMEM/F12 supplemented with $2.5 \mathrm{mM}$, L-glutamine, $200 \mu \mathrm{g} / \mathrm{ml}$ gentamicin, $25 \mu \mathrm{g} / \mathrm{ml}$ fungizone and $10 \%$ bovine calf serum. Cell number and viability were determined using a hemocytometer with trypan blue exclusion. The freshly-isolated cells were grown to confluence in T75 flasks and then retrieved by trypsin digestion. The first passage chondrocytes were used in this study.

Chondrocyte adhesion and culture

Chondrocytes were seeded to polymer-coated glass dishes $\left(1 \times 10^{4} \mathrm{cells} / \mathrm{cm}^{2}\right)$, and then cultured in a humidified $37^{\circ} \mathrm{C}$, $5 \% \mathrm{CO}_{2}$ incubator. Culture medium was changed every 2 or 3 days. After incubation for 1,7 or 14 days, the plates were rinsed with PBS twice and adherent chondrocytes were lysed in $10 \mathrm{mM}$ EDTA solution ( $\mathrm{pH} 12.0)$ and then the lysate was neutralized with $1 \mathrm{~N} \mathrm{KH}_{2} \mathrm{PO}_{4}$ solution ( $\mathrm{pH} 4.0$ ). The number of adherent cells was determined by a Hoechst 33258 assay [21]. Briefly, $100 \mu \mathrm{l}$ of cell lysate were mixed with 1 $\mathrm{ml}$ of Hoechst 33258 solution $\left(0.05 \mu \mathrm{g} / \mathrm{ml} \mathrm{H}_{2} \mathrm{O}\right)$ and then the fluorescence at $456 \mathrm{~nm}$ was measured at the excitation wavelength $348 \mathrm{~nm}$. A series of known numbers of chondrocytes (determined by a hemocytometer) was used to generate a calibration curve, and the numbers of adherent cells were determined by interpolation. Twelve-well tissue culture polystyrene plates (TCPS, Costar cat. no. 3513) were used as control.

RNA harvest and RT-PCR (Reverse TranscriptasePolymerase Chain Reaction) analysis

The expression of $\beta$-actin, type I collagen, type II collagen and aggrecan was analyzed by RT-PCR analysis. After the cells were removed from the substrates, the total RNA of chondrocytes cultured on plasma-treated or untreated TCPS was extracted by using a single-step method modified from an acid guanidinium-thiocyanate-phenol-chloroform extract procedure developed by Chomczyski and Sacchi [22]. Briefly, the chondrocytes were lysed in $1 \mathrm{ml}$ of REzol ${ }^{\mathrm{TM}} \mathrm{C} \& \mathrm{~T}$ reagent (PROtech Technology Ent. Co., Taipei, Taiwan) and total RNA was subsequently isolated according to the manufacturer's instructions. Complementary DNA (cDNA) was synthesized from $1 \mu \mathrm{g}$ of total RNA by SUPERSCRIPT ${ }^{\mathrm{TM}}$ II, RNase $\mathrm{H}^{-}$Reverse Transcriptase (Cat. no. 18064-014, Invitrogen) using and oligo-(dT) priming, and incubated at $42^{\circ} \mathrm{C}$ for $50 \mathrm{~min}$.

The cDNA was then used as the temperate for PCR amplification. The primer sequences and the length of PCR products for $\beta$-actin, type I collagen, type II collagen and aggrecan are listed as followed: $\beta$-actin: forward-AAGGGCTCCGGCATGTGC, reverseGGGCAGGGGTGTTGAAGG (360 bp)

Type I collagen: forward-GCTGGCCAACTATGCCTC, reverse-GAAACAGACTGGGCCAATG (318 bp)

Type II collagen: forward-TGCCTACCTGGACGAAGC, reverse-CCCAGTTCAGGCTCTTAG (449 bp)

Aggrecan: forward-CTGTTACCGCCACTTCCC, reverse-GGTGCGGTACCAGTGCAC (441 bp)

Amplification was performed in a Gene Amp PCR System 9600 thermocycler for 35 cycles of $95^{\circ} \mathrm{C} / 1$ min denaturation, $55^{\circ} \mathrm{C} / 1 \mathrm{~min}$ annealing and $72^{\circ} \mathrm{C} / 1 \mathrm{~min}$ extension, using recombinant Taq DNA polymerase (Promega, Cat. no. M1861).

The PCR products were analyzed by electrophoresis in a $1 \%$ agarose gel. After stained with ethium bromide, the images of resulting bands were taken under UVtransillumination using Kodak Digital Science DC120 camera. The intensities of bands were analyzed by ONE-DScan for Windows (Spectra Services Inc. Webster, NY, USA). The intensities of the bands for type I collagen, type II collagen and aggrecan were normalized to the intensity of the band for $\beta$-actin from the chondrocytes grown on the same surface. The expression of mRNA in the primary chondrocytes prior to seeding was also determined and used as controls.

Statistics

Statistical assessment of significant variations was performed by GraphPad Instat ${ }^{\circledR} 3.00$ (GraphPad Software Inc.). Unpaired $t$-test was conducted to determine $p$-values. All data were reported as mean $\pm \mathrm{SD}$.

\section{Results}

Polymer coating

Biodegradable polymers were coated to glass surfaces by solvent casting. Since adhesivity of the biodegradable polymers to glass surfaces was poor, polymer films were prone to delaminate from glass substrates after incubation in culture medium for several days. Therefore, before polymer casting, glass surfaces were precoated with a layer of hydrophobic silane, which enhanced the adhesivity between the biodegradable polymers and glass substrates. Table 1 shows the measured water contact angles of the untreated glass, the silane-treated glass, and the polymer-coated surfaces. The changes in static water contact angles indicated the formation of polymer films.

Chondrocyte adhesion and proliferation on the biodegradable films

Figure 1 shows a representative result for 1-day chondrocyte adhesion to biodegradable substrates. The number of 
Table 1 Static contact angles of water on samples evaluated at $24^{\circ} \mathrm{C}$ using a contact angle meter with a goniometer. Data represent mean $\pm \mathrm{SD}$ $(n=6)$

\begin{tabular}{llllll}
\hline Glass & Silane-Treated glass & PDLLA & PLLA & PLGA & PCL \\
\hline $35.4^{\circ} \pm 3.4^{\circ}$ & $93.4^{\circ} \pm 1.2^{\circ}$ & $70.8^{\circ} \pm 1.1^{\circ}$ & $77.2^{\circ} \pm 3.3^{\circ}$ & $91.35^{\circ} \pm 1.2^{\circ}$ & $72.8^{\circ} \pm 0.4^{\circ}$ \\
\hline
\end{tabular}

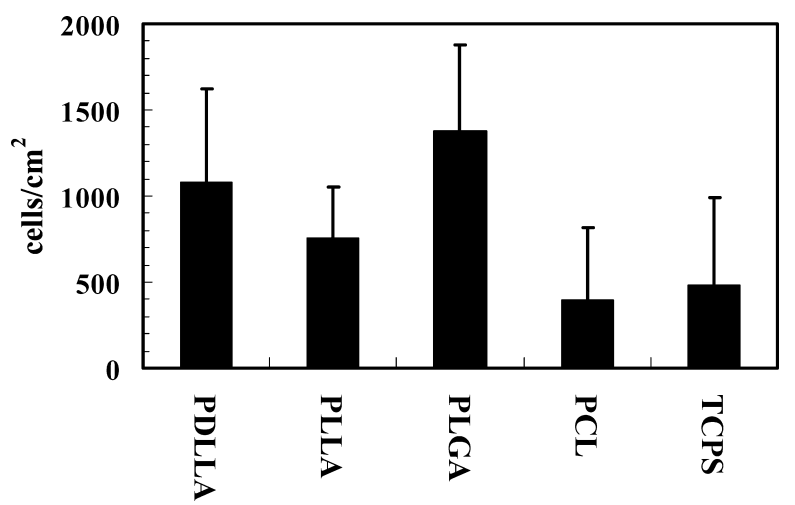

Fig. 1 Chondrocyte adhesion to degradable polymers after 1 day. Cell seeding density was $1 \times 10^{4}$ cells $/ \mathrm{cm}^{2}$. Error bars $=$ standard deviation $(n=4)$.

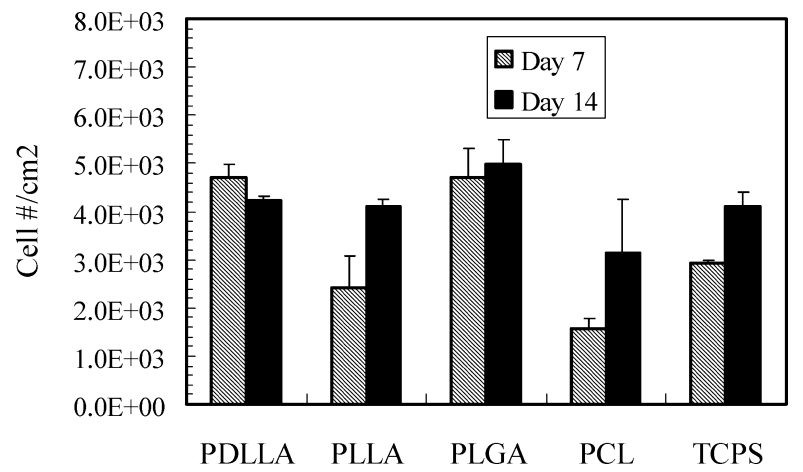

Fig. 2 The cell numbers on the degradable polymers on Day 7 and Day 14. Cell seeding density was $1 \times 10^{4}$ cells $/ \mathrm{cm}^{2}$. Error bars $=$ standard deviation $(n=4)$.

cells on these surfaces was in the order: PLGA $>$ PDLLA $>$ PLLA $>$ TCPS $>$ PCL. However, the difference was not significant $(p>0.05)$.

Fig. 2 shows a typical result for cell proliferation on biodegradable films. On day 7, the cell numbers on either PDLLA or PLGA were significantly higher than those on PLLA or PCL $(p<0.001)$. However, the difference in cell numbers between different polymers was decreased from day 7 to day 14 . Although the order in cell numbers on the polymer surfaces was PLGA $>$ PDLLA $\geqq$ TCPS $\geqq$ PLLA $>$ PCL on Day 14 , there was no significant difference between cell numbers $(p>0.05)$.

\section{Gene expression analysis by RT-PCR}

RT-PCR was chosen in this study to evaluate the gene expression levels for type I collagen, type II collagen and aggrecan.

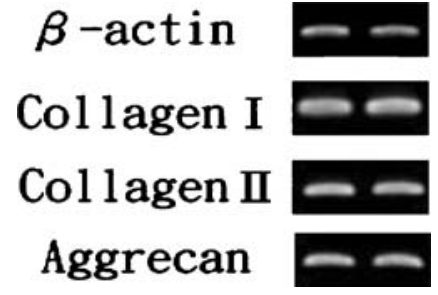

Fig. 3 Electrophoresis images for RT-PCR analysis of the genes encoding $\beta$-actin, type I collagen, type II collagen, and aggrecan in chondrocytes. The two lanes for each gene represent duplicates for each sample.

Figure 3 shows electrophoresis images of the PCR products for $\beta$-actin, type I collagen, type II collagen and aggrecan. The lengths of the PCR products were as designed.

The intensities of the bands for type I collagen, type II collagen and aggrecan were normalized by dividing the intensities of the band for $\beta$-actin to eliminate the difference in the cell numbers. We know that this semi-quantitative approach is not a perfect tool to determine the amount of mRNA synthesis, but since each of the two sets of RT-PCR results has been repeated thrice, the results should represent the gene expression levels.

Primary chondrocytes isolated from porcine cartilage were used in this study. We found that gene expression patterns of the investigated proteins were varied in cells from different sources. Figures 4 and 5 show representative data for the expression of type I collagen, type II collagen and aggrecan genes in two sets of experiments, between which the phenotype of chondrocytes prior to seeding was different (see Control bars in Figs. 4 and 5). In the first set (Fig. 4), although the chondrocytes prior to seeding expressed type I collagen (the leftmost bar in Fig. 4A), these cells still expressed type II collagen (the leftmost bar in Fig. 4B) and aggrecan (the leftmost bar in Fig. 4C). One the other hand, in the second set the chondrocytes seeding only expressed type I collagen prior to seeding (the leftmost bar in Fig. 5A) and expression of type II collagen (the leftmost bar in Fig. 5B) or aggrecan (the leftmost bar in Fig. 5C) was not detectable.

In the first set of experiment, type I collagen expression level was decreased with time on all substrates (Fig. 4A). The relative intensity for type I collagen expression was low on PLGA and PCL surfaces compared to PDLLA and PLLA ones on Day 7. On Day 7, type I collagen expression was almost undetectable on all surfaces except PLLA. The expression of type II collagen and aggrecan was detectable on PLGA and PCL surfaces on Day 7, but was undetectable 

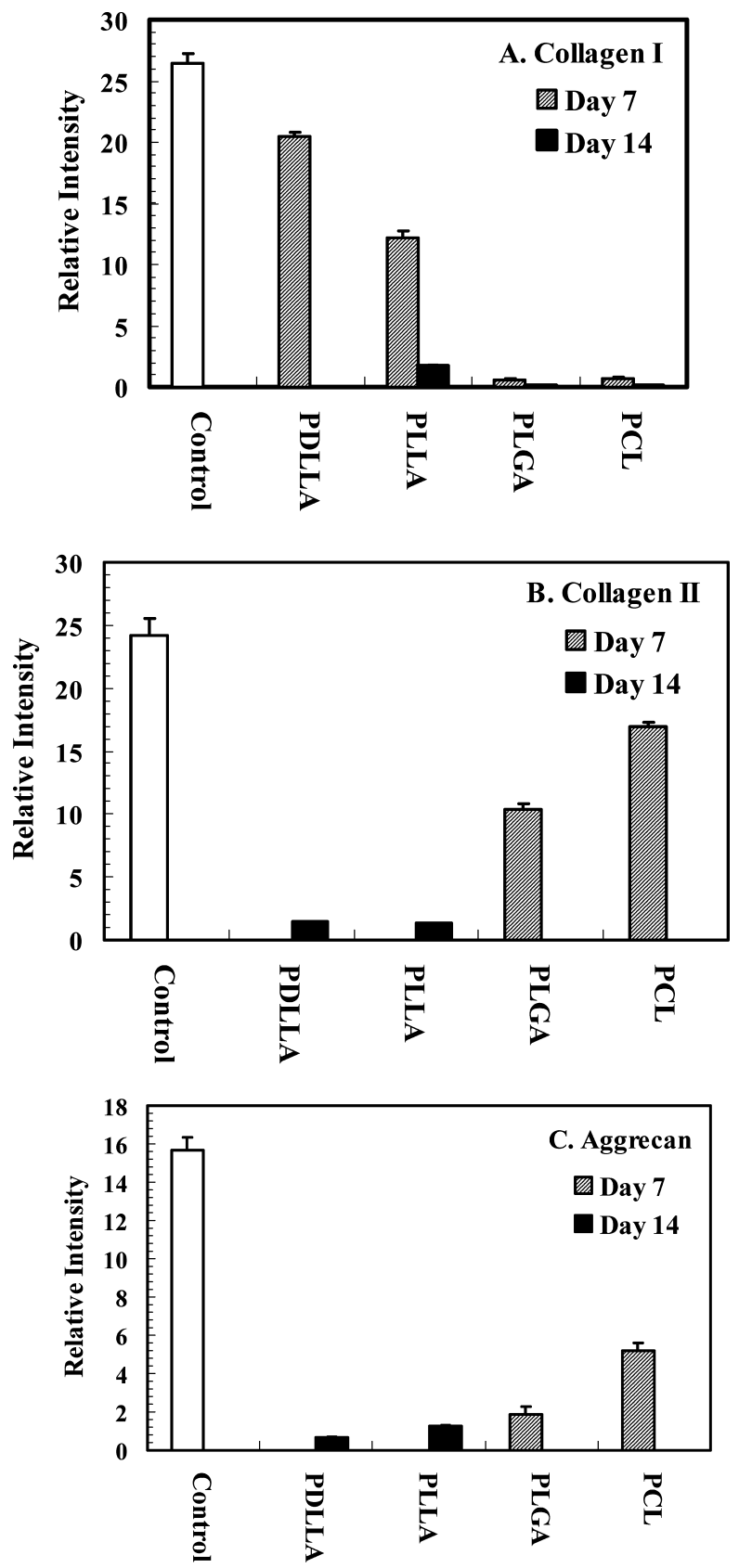

Fig. 4 The normalized band intensity for type I collagen (A), type II collagen (B) and aggrecan (C) PCR products for the first set of experiments. The error bars represents three independent RT-PCR experiments.

on Day 14 (Figs. 4B and 4C). Differently, expression of type II collagen and aggrecan was undetectable on the PDLLA and PLLA surfaces on Day 7, but was induced on Day 14.

In the second set of the experiment, type I collagen gene was expressed on all surfaces at different levels (Fig. 3B). Until 14 day, expression of type I collagen was still found on all surfaces. Expression of type II collagen or aggrecan was undetectable at most of the conditions, except on PLGA surfaces on Day 7 and PDLLA surfaces on Day 14 (Figs. 4B and $5 \mathrm{~B})$.
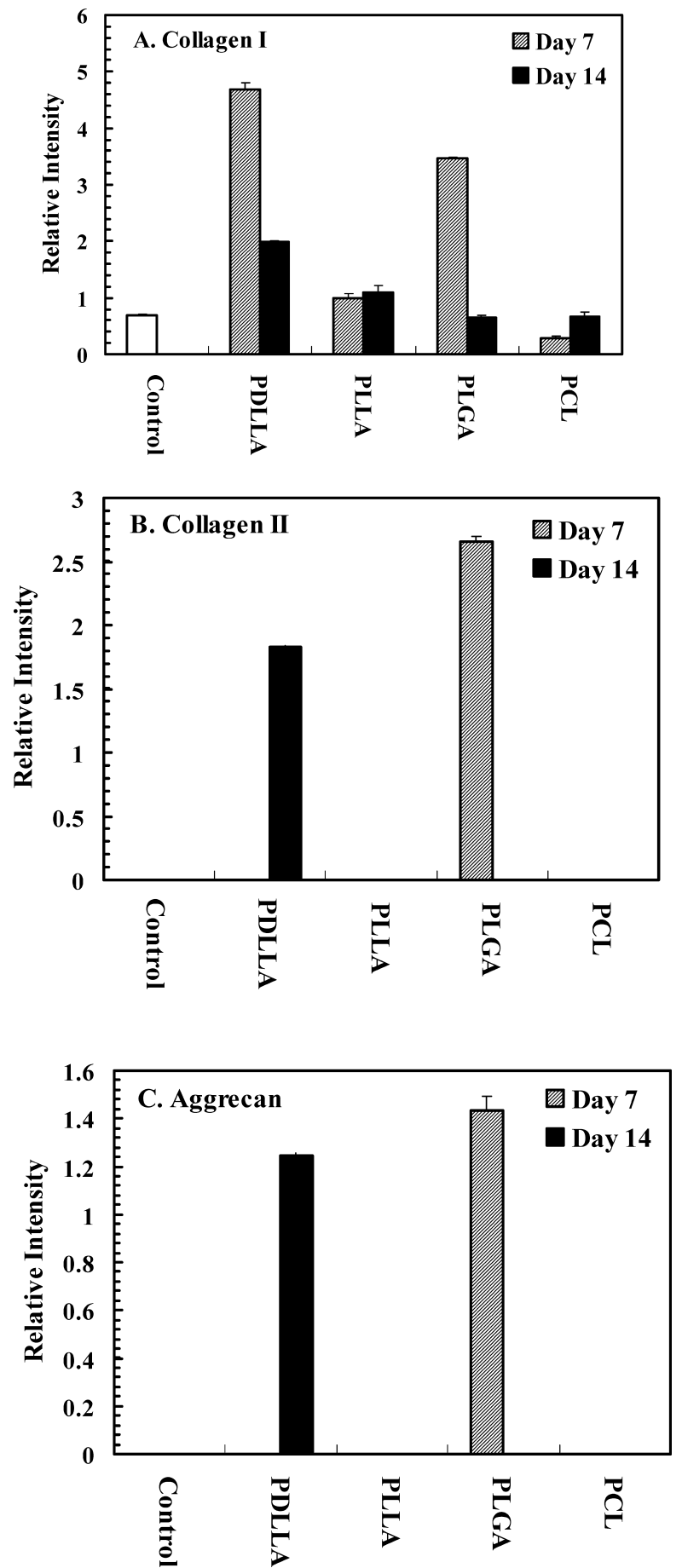

Fig. 5 The normalized band intensity for type I collagen (A), type II collagen (B) and aggrecan (C) PCR products for the second set of experiments. The error bars represents three independent RT-PCR experiments.

\section{Discussion}

One challenge in fabricating an appropriate scaffold for tissue engineered cartilage is searching a suitable material that not only supports chondrocyte adhesion and 
proliferation but also maintain chondrocyte differentiated phenotype. Therefore, knowledge of how a specific material affects chondrocyte growth and synthesis of chondrocytespecific ECM protein is important in leading to constructing an ideal scaffold for cartilage tissue-engineering application. In this study, chondrocyte interaction with several commonly used biodegradable polymers was investigated, with respect to adhesion, proliferation and gene expression was investigated.

All of the biodegradable polymers investigated in this study are polyesters and therefore have similar chemistries. The polymer physiochemical characteristics are affected by monomer composition, polymer architecture, and molecular weight. The major difference between these polymers is the number and location of methyl and oxygen groups incorporated into their backbone. PCL contains more methyl groups along its backbone, which may contribute to its hydrophobicity. The major difference between PDLLA and PLLA is their crystallinity, an important factor in polymer biodegradation. The racemic DL polymer is less crystalline than the L-lactide homopolymers, resulting in amorphous PDLLA more liable to hydrolysis.

Chondrocytes adhered to PDLLA or PLGA was better than those to PLLA or PCL (Fig. 1) in spite of no significance. However, this trend was also observed from previous studies [13, 14], which compare human or rabbit chondrocytes adhered to a series of biodegradable polymer films. Besides cell adhesion, cell growth after 7-day incubation on PDLLA or PLGA was significantly higher than that on PLLA or PCL $(p<0.001)$ (Fig. 2). The trend continued to Day 14 despite of the fact that the difference in cell numbers was not significant $(p>0.05)$. Therefore, PDLLA or PLGA is more biocompatible than PLLA or PCL regarding chondrocyte adhesion and growth.

It is generally accepted that the physiochemical properties of substrates influence cell adhesion and growth. For example, surface wettability is considered to strongly influence cell adhesion and proliferation on a surface [23-27]. However, we could not find a correlation between chondrocyte adhesion and surface hydrophobicity of the polyesters. The same conclusion was also found in a previous study [13]. On the other hand, our result supports another study which suggests that chondrocyte attachment and growth are correlated positively with the polymer degradation rates [14]. In the current study, the attachment and short-term growth (7 days) of chondrocytes were better on the polyesters with higher degradation rates, PDLLA and PLGA, than on the polyesters with lower degradation rates, PLLA and PCL. Particularly, while PCL degrades much more slowly than other $\operatorname{poly}(\alpha-$ hydroxy acid)s [28], chondrocytes performed worst on PCL among these materials. Our result confirms a previous study that partial surface hydrolysis of PLGA films increased osteoblast and chondrocyte adhesion [29]. Hydrolysis of polyesters could increase surface functionality and charges. For example, it has been shown that $\mathrm{NaOH}$ treatment of polyesters increased surface carboxylic acid density, thus enhancing hydrophilicity of polyester surfaces [30]. The enhancement effects may be via cell direct interaction with surface functionality, or via indirect interaction through adsorbed serum adhesive proteins such as fibronectin and vitronectin to the substrates.

Another important aspect in chondrocyte culture in scaffolds is production of tissue-specific ECM proteins. Production of tissue-specific ECM proteins can be evaluated at two levels: the gene transcriptional level and the protein synthesis level. A positive correlation between these two levels was found from previous studies from Grande's group [11, 31]. Based on RT-PCR results, the expression of mRNAs for type I collagen, type II collagen and aggrecan were transient and changed with time. For example, the expression of type I collagen was high on day 7 but decreased on day 14 (Fig. 4A). The expression of type II collagen on the PLGA or PCL substrates was high on day 7, but ceased on day 14. Previously, Grande's group showed a similar transient pattern of gene expression [31]. They found that type I collagen was not expressed on the PLLA and PGA matrices at $48 \mathrm{~h}$, but moderately induced on the PLLA at $72 \mathrm{~h}$. Type II collagen was up-regulated at $72 \mathrm{~h}$ post cell seeding on PLA or PGA scaffolds, but was not further expressed at $96 \mathrm{~h}$. Since mRNA expression is transient, it must be careful to use it as an index of cell phenotype.

We found that gene expression of chondrocytes cultured on the polymer films is related to the differentiated status of chondrocytes prior to seeding. The phenotypic characteristics of chondrocytes isolated from adult pigs may be varied from one pig to another, resulting in the discrepancy in the RT-PCR results using different cell sources. The chondrocytes used in the first set still expressed type II collagen and aggrecan at the moment of seeding, whereas those in the second set did not express type II collagen and aggrecan, indicating completely de-differentiated phenotype. In the first set of RT-PCR experiments, chondrocytes expressed type II collagen and aggrecan after cultured on PLLA (Day 14) and PCL (Day 7) (Figs. 4B and 4C), while the cells in the second set did not express type II collagen or aggrecan on these two surfaces (Figs. 5B and 5C). The results suggest the phenotype of chondrocytes at the moment of seeding is important for later ECM protein expression. Besides, chondrocytes expressed type II collagen and aggrecan on PDLLA (Day 14) and PLGA (Day 7) no matter which kinds of chondrocytes were used, inferring that PDLLA and PLGA might be more suitable for inducing chondrocytic phenotype than PLLA and PCL.

It is noted that the expression of type II collagen and aggrecan genes is up-regulated or down-regulated concurrently on each material (comparing Figs. 4B and 4C, and 
Figs. 5B and 5C). It could be due to that the expression of Col2a1 and aggrecan is regulated by the same transcript factor, Sox9 [32]. Sox9 is required for chondrocyte differentiation and for expression of a number of chondrocytespecific marker genes, including type II collagen and aggrecan.

\section{Conclusion}

PDLL and PLGA, which degrade faster than PLLA and PCL, showed better biocompatibility to chondrocytes than the latter two materials. Furthermore, PDLLA and PLGA supported the expression of chondrocyte specific ECM proteins, type II collagen and aggrecan, better than PLLA and PCL. These finding suggest that PDLLA and PLGA seem to be better materials compared to PLLA and PCL for cartilage tissue engineering. Furthermore, $\mathrm{PCL}$ is apparently not a good candidate for cartilage tissue engineering due to its poor cell compatibility, i.e. not supporting cell adhesion, growth and expression of chondrocyte ECM proteins. Certainly, the conclusion based on two-dimensional surfaces cannot always predict chondrocyte behavior in a three-dimensional environment. Further studies on three-dimensional scaffolds are needed.

Acknowledgements The authors sincerely appreciate the financial support from National Science Council, Taiwan (NSC91-2218-E-002032).

\section{References}

1. A. I. CAPLAN, Sci Am 251 (1984) 84.

2. A. I. CAPLAN, M. ELYADERANI, Y. MOCHIZUKI, S. W A KITANI and V. M. GOLDBER G, Clin. Orthop. (1997) 254.

3. S. W. O' DRISCOLL, F. W. KEELEY and R. B. S ALTER, J. Bone. Joint. Surg. Am. 68 (1986) 1017.

4. E. BELL, in "Principles of Tissue Engineering" (Academic Press, USA, 2000). p. xxxv.

5. J. A. HUB B ELL, Bio-Technology 13 (1995) 565.

6. L. E. FREED, G. VUNJAK-NOVAKOVIC, R. J. BIRON, D. B. EAGLES, D. C. LESNOY and S. K. B ARLOW, et al., Biotechnology (N Y) 12 (1994) 689.

7. L. G. CIMA, J. P. VACANTI, C. VACANTI, D. INGBER, D. MOONEY and R. LANGER, J. Biomech. Eng. 113 (1991) 143.
8. L. E. FREED, J. C. MARQUIS, A. NOHRIA, J. EMMANUAL, A. G. MIKOS and R. LANGER, J. Biomed. Mater. Res. 27 (1993) 11.

9. N. A. PEPPAS and R. LANGER, Science 263 (1994) 1715.

10. S. PULAPURA and J. KOHN, J. Biomater. Appl. 6 (1992) 216.

11. D. A. GRANDE, C. HALBERSTADT, G. NAUGHTON, R. SCHWARTZ and R. MANJI, J. Biomed. Mater. Res. 34 (1997) 211.

12. M. SitTinger, D. REITZEL, M. DAUNER, H. HIERLEMANN, C. HAMMER and E. KASTENBAUER, et al., J. Biomed. Mater. Res. 33 (1996) 57.

13. S. L. ISHAUG-RILEY, L. E. OKUN, G. PRADO, M. A. APPLEGATE and A. RATCLIFFE, Biomaterials 20 (1999) 2245.

14. S. H. HSU, C. L. TSAI and C. M. TANG,Artif. Organs 26 (2002) 647.

15. K. VON DER MARK, V. GAUSS, H. VON DER MARK and P. MULLER, Nature 267 (1977) 531.

16. P. BENYA, J. SCHAFFER, Cell 30 (1982) 215.

17. K. ELIMA, E. VUORIO, FEBS Lett. 258 (1989) 195.

18. V. LEFEBVRE, C. PEETERS-JORIS and G. VAES, Biochim. Biophys. Acta. 1051 (1990) 266.

19. C. W. ARCHER, J. MCDOWELL, M. T. BAYLISS, M. D. Stephens and G. BENTLEY, J. Cell. Sci. 97 (Pt 2) (1990) 361.

20. A. L. Aulthouse, M. BECK, E. GRIFFey, J. SANFORD, K. ARDEN and M. A. MACHADO, et al., In Vitro Cell Dev. Biol. 25 (1989) 659.

21. Y. J. KIM, R. L. SAH, J. Y. DOONG and A. J. GRODZINS K Y, Anal. Biochem. 174 (1988) 168.

22. P. CHOMCZYNSKI and N. SACCHI, Anal. Biochem. 162 (1987) 156.

23. T. A. HORBETT and M. B. SCHWAY, J. Biomed. Mater. Res. 22 (1988) 763.

24. M. D. EVANS and J. G. STEELE, J. Biomed. Mater. Res. 40 (1998) 621.

25. S. I. ERTEL, B. D. RATNER and T. A. HORBETT, $J$. Biomed. Mater. Res. 24 (1990) 1637.

26. T. A. HORBETT, J. J. WALDBURGER, B. D. RATNER and A. S. HOFFMAN, J. Biomed. Mater. Res. 22 (1988) 383.

27. W.-B. TSAI, T.-C. WEI, M.-C. LIN, J.-Y. WANG and C.-H. CHENM, J. Biomater. Sci. Polym. Edn. 16 (2005) 699.

28. C. G. PITT, T. A. MARKS and A. SCHINDLER, in "Controlled Release of Bioactive Materials" (Academic Press, Inc., New York, 1980). p. 19.

29. S. KAY, A. THAPA, K. M. HABERSTROH and T. J. WEB S TER, Tissue Eng. 8 (2002) 753.

30. J. GAO, L. NIKLASON and R. LANGER, J. Biomed. Mater Res. 42 (1998) 417.

31. V. SALDANHA and D. A. GRANDE, Biomaterials 21 (2000) 2427.

32. B. DE CROMbrugGhe, V. LEFEBVRE, R. R. BEHRINGER, W. BI, S. MURAKAMI and W. HUANG, Matrix Biol. 19 (2000) 389. 